\title{
Advanced airway management and respiratory care in decompensated pulmonary hypertension
}

\author{
Cyrus A. Vahdatpour ${ }^{1}$ (1) . John J. Ryan ${ }^{2}$. Joshua M. Zimmerman ${ }^{3}$. Samuel J. MacCormick ${ }^{4}$ Harold I. Palevsky ${ }^{5}$. \\ Hassan Alnuaimat ${ }^{1} \cdot$ Ali Ataya ${ }^{1}$
}

Accepted: 25 August 2021 / Published online: 2 September 2021

(c) The Author(s), under exclusive licence to Springer Science+Business Media, LLC, part of Springer Nature 2021

\begin{abstract}
Meticulous risk stratification is essential when considering intubation of a patient with decompensated pulmonary hypertension $(\mathrm{dPH})$. It is paramount to understand both the pathophysiology of $\mathrm{dPH}$ (and associated right ventricular failure) and the complications related to a high-risk intubation before attempting the procedure. There are few recommendations in this area and the literature, guiding these recommendations, is limited to expert opinion and very few case reports/case series. This review will discuss the complex pathophysiology of $\mathrm{dPH}$, the complications associated with intubation, the debates surrounding induction agents, and the available options for the intubation procedure, with specific emphasis on the emerging role for awake fiberoptic intubation. All patients should be evaluated for candidacy for veno-arterial extracorporeal membrane oxygen as a bridge to recovery, lung transplantation, or pulmonary endarterectomy prior to intubation. Only an experienced proceduralist who is both comfortable with high-risk intubations and the pathophysiology of dPH should perform these intubations.
\end{abstract}

Keywords Intubation $\cdot$ Decompensated pulmonary hypertension $\cdot$ Respiratory failure $\cdot$ Cardiogenic shock

\section{Introduction}

Pulmonary hypertension (PH) is characterized by progressive pulmonary vascular remodeling resulting in increased pulmonary vascular resistance (PVR). This results in increased right ventricular (RV) afterload, which stimulates adaptive RV remodeling and may progress to RV failure. $\mathrm{PH}$ is diagnosed by a mean pulmonary arterial pressure (mPAP) of $>20 \mathrm{mmHg}$ on right heart catheterization [1].

Cyrus A. Vahdatpour

Cyrus.vahdatpour@medicine.ufl.edu

1 Department of Pulmonary, Critical Care, and Sleep Medicine, University of Florida, P.O Box 100225 JHMHC, Gainesville, FL 32610-0225, USA

2 Division of Cardiovascular Medicine, University of Utah, Salt Lake City, UT, USA

3 Department of Anesthesiology, University of Utah, Salt Lake City, UT, USA

4 Department of Anesthesiology, University of Virginia, Charlottesville, VA, USA

5 Division of Pulmonary, Allergy and Critical Care, University of Pennsylvania, Philadelphia, PA, USA
Pre-capillary PH is defined with a PVR of $\geq 3$ wood units and a pulmonary arterial wedge pressure (PAWP) $\leq 15 \mathrm{mmHg}$. For the purposes of this paper, we will discuss $\mathrm{PH}$ in the context of pre-capillary $\mathrm{PH}$.

There is no formal hemodynamic definition of acutely decompensated $\mathrm{PH}(\mathrm{dPH})$ although it is commonly described by association with hemodynamic instability and with the use of inotropic agents and vasopressors. However, a descriptive definition characterizes $\mathrm{dPH}$ as a constellation of signs and symptoms that suggest inadequate cardiac output (CO) and/or increased central venous pressure (CVP) secondary to increased RV afterload [2,3]. In order to determine best practice, $\mathrm{dPH}$ would benefit from a more formalized definition, similar to what is used in cardiogenic shock. Cardiogenic shock uses a combination of the following: (a) systolic blood pressure (SBP) $<90 \mathrm{mmHg}$ for $>30 \mathrm{~min}$ or vasopressor support to maintain a $\mathrm{SBP}>90 \mathrm{mmHg}$, (b) clinical evidence of end-organ damage (i.e., decreased urine output, altered mental status, cool extremities, jugular venous distention, serum lactic acid $>2 \mathrm{mmol} / \mathrm{L}$, elevated serum creatinine, transaminitis), and (c) the use of hemodynamic criteria (i.e., cardiac index $<2.2 \mathrm{~L} / \mathrm{min} / \mathrm{m}^{2}$ or PCWP $>15 \mathrm{mmHg}$ ) [4]. Additional hemodynamic criteria 
Table 1 Proposed definition for decompensated pulmonary hypertension

\begin{tabular}{ll}
\hline Criteria & Supportive clinical or hemodynamic findings \\
\hline Hypotension & $\begin{array}{c}\text { Systolic blood pressure }<90 \mathrm{mmHg} \text { for }>30 \text { min despite volume opti- } \\
\text { mization or requirement of vasopressors to maintain systolic blood } \\
\text { pressure of }>90 \mathrm{mmHg} \\
\text { Jugular venous distension/hepatojugular reflux }\end{array}$ \\
$\begin{array}{l}\text { Evidence of end organ dysfunction or damage secondary to right } \\
\text { ventricular failure }\end{array}$ & $\begin{array}{l}\text { Decreased urinary output/elevated creatinine from baseline } \\
\text { Transaminitis secondary to congestive hepatopathy }\end{array}$ \\
& $\begin{array}{l}\text { Elevated lactic acid }>2 \text { mmol/L } \\
\text { Altered mental status }\end{array}$ \\
& $\begin{array}{l}\text { Cool extremities } \\
\text { Reduced capillary refill }\end{array}$ \\
& Evidence of right-sided filling pressures* \\
Cardiac catheterization or echocardiography & RAP/PCWP ratio $>0.5$ \\
\hline
\end{tabular}

Criteria within all three categories should be present to accurately suggest $\mathrm{dPH}$

*Evidence of right-sided filling pressures with echocardiography include right atrial pressure (RAP) $>20 \mathrm{mmHg}$, right atrial area enlargement (end-systole) $>18 \mathrm{~cm}^{2}$, inferior vena cava diameter $>21 \mathrm{~mm}$ with decreased inspiratory collapse, right ventricle to left basal diameter ratio $>1.0$, and flattening of the interventricular septum

for RV failure (RVF) should be considered that includes a right atrial pressure/PCWP ratio $>0.5$ [5]. A proposed definition for $\mathrm{dPH}$ is represented in Table 1 and emphasizes markers of RVF. Currently, dPH primarily remains a clinical diagnosis and exists as a continuum of pre-shock physiology to refractory hemodynamic instability.

Acute respiratory failure (ARF), as defined by a new onset of respiratory insufficiency with evidence of hypoxia and/or hypercapnia, is a common finding amongst dPH patients. When emergent endotracheal intubation (ETI) is necessary, it is associated with a high risk of hemodynamic deterioration and death (Fig. 1) [6]. PH patients with ARF commonly experience systemic hypotension and hypoxia due to a combination of their underlying acute and chronic pathophysiology often within $1 \mathrm{~h}$ of intubation [7]. These are often worsened during intubation, possibly from a combination of the following: (a) the effects of sedatives administered for intubation, (b) peri-intubation attempts at lung recruitment via noninvasive positive pressure ventilation (NIPPV), and (c) during the transition from spontaneous to positive pressure ventilation after intubation. As an effort at lung recruitment, NIPPV may increase PVR through hyperinflation, and the positive intrathoracic pressure in turn have effects on venous return and RV afterload.

ARF requiring ETI is associated with increased risk of cardiovascular collapse [8]. ETI is associated with increased mortality in hypotensive patients without $\mathrm{RV}$ failure [9] and increased risk for cardiac arrest in
Fig. 1 Challenges and complications associated with endotracheal intubation

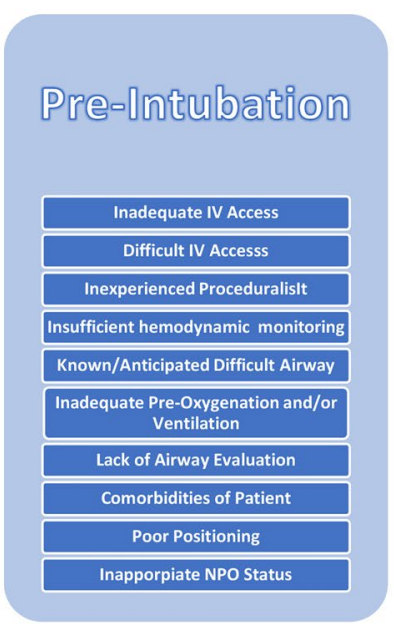

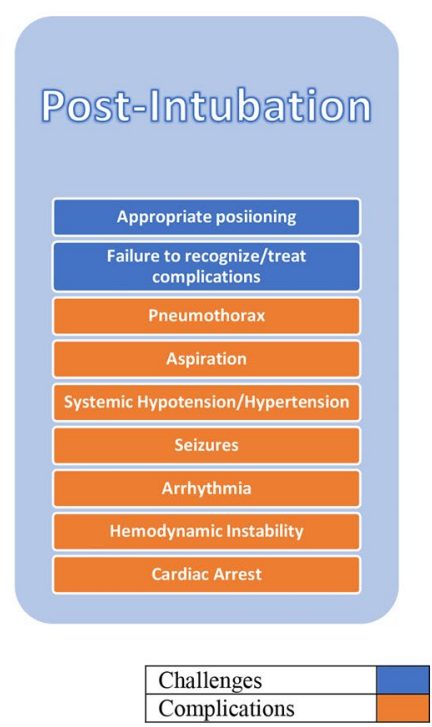


hypoxemic patients $[8,10,11]$. The critically ill cohort is subject to technical difficulty requiring repeat attempts in roughly one-third of patients undergoing ETI [12]. Complicating the situation, delaying ETI with noninvasive ventilation (NIV) trials is associated with increased mortality $[8,13,14]$. There is a paucity of evidence specifically dedicated to $\mathrm{dPH}$ and emergent ETI. It is commonly recommended to avoid intubation, if possible, in $\mathrm{dPH}$ patients $[15,16]$, but this is based primarily on anecdotal experience. This review aims to elucidate the concerns surrounding ETI in dPH patients and emphasizes that intubation in this population should be performed by an experienced proceduralist.

\section{Pathophysiology}

\section{RVF in chronic pulmonary hypertension}

Chronic RV failure in PH is related to the inability of the $\mathrm{RV}$ to adapt to a progressively increased afterload developing as a consequence of progressive pulmonary vascular remodeling. Chronic increase in RV afterload causes RV wall stress that propagates adaptive myocardial remodeling through concentric hypertrophy. As RV tension increases, RV wall hypertrophy develops and progresses. Eccentric RV hypertrophy eventually occurs in order to reduce RV wall tension [3]. This is maladaptive and correlates with clinical manifestations, such as progressive exertional dyspnea or syncope, and the predisposition towards acute RV failure/ $\mathrm{dPH}$.

Right ventriculo-arterial (VA) coupling describes a state of energy transfer from the RV to the pulmonary vasculature. In PH, VA coupling is generally preserved in the early stages of RV remodeling. VA coupling correlates with pulmonary artery compliance, as a compliant pulmonary artery preserves RV function and a poorly compliant pulmonary artery promotes RV failure [17]. As $\mathrm{PH}$ progresses, RV function eventually becomes maladaptive-adversely impacting the pulmonary vascular load such that energy transfer becomes less efficient. This process is called right VA uncoupling and is described by decreased RV End-Systolic Elastance $\left(\mathrm{E}_{\mathrm{es}}\right) /$ Aterial Elastance $\left(\mathrm{E}_{\mathrm{a}}\right)$. This ratio is used to assess how $\mathrm{RV}$ contractility is adapted to afterload. Normal value of this ratio is considered to be 1.5 to 2.0. A ratio of $<0.8$ is considered to reflect substantial RV maladaptation and a $\mathrm{RV}$ ejection fraction less than 35\% [18]. VA uncoupling correlates with impending RV failure, increasing RV volume and mass, and distensibility/capacitance of the pulmonary arteries $[18,19]$. Measurements of right VA coupling on right heart catheterization, cardiac magnetic resonance imaging, and echocardiography are a current area of investigation for intervention and prognostication.

\section{Decompensated RVF}

Over time, most patients with PH become increasingly susceptible to decompensate, which is commonly caused by disease progression, pulmonary embolism, infection, volume overload, arrhythmias, anemia, hypercarbia, or acid-base disturbances. These processes are associated with an acute increase in RV afterload, which increases RV myocardial oxygen demand, disrupts systolic and diastolic RV coronary perfusion, promotes septal displacement into the left ventricle (ventricular interdependence), and increases right atrial pressures causing venous congestion of vital organs. Clinically, this is characterized by peripheral edema, jugular venous distension, hypotension, tachycardia, and respiratory distress. These clinical findings are accompanied by evidence of multisystem organ failure-commonly involving the kidneys, liver, and gastrointestinal tract [15].

\section{Pathophysiology of intubation in the $\mathrm{dPH}$ patient}

$\mathrm{PH}$ is associated with an increased risk of hemodynamic instability during and shortly after ETI [6, 20-23]. Atelectasis, hypoxemia, and hypercapnia are complications that increase PVR as a consequence of deep sedation and supine positioning for direct laryngoscopy (DL). It is inferred that placing the patient in the supine position during intubation may increase RV preload, increase RV distention, reduce RV output, and exacerbate systemic hypotension [24-27]. Therefore, positioning the patient at an incline during DL or video laryngoscopy (VAL) for intubation should be considered. Induction with anesthetic agents lead to systemic vasodilation which can decrease coronary artery perfusion. The combination of increased myocardial oxygen demand and decreased coronary perfusion induce right ventricular ischemia, which can trigger hemodynamic collapse during intubation [7]. Consideration of conscious sedation as opposed to rapid sequence intubation (RSI) or not using any sedation should be considered prior to intubation.

Atelectasis causes impaired oxygenation and reduced pulmonary compliance [28]. Both can increase PVR and $\mathrm{RV}$ afterload by promoting hypoxic vasoconstriction and increasing pressures within the pulmonary circuit. Prior to intubation, physicians often attempt to reduce atelectasis by upright positioning of the patient and NIPPV trials. Upright positioning will reduce RV preload and allow gravity to expand the lungs. NIPPV provides positive end-expiratory pressure (PEEP), which recruits 
compressed alveoli to participate in oxygenation at the expense of increasing intra-thoracic pressures. NIPPV has been correlated with a reduction in SBP, mPAP, and CO in a small study of 33 stable patients with either precapillary or post capillary PH [29]. This suggests cautious NIPPV use in dPH patients. Larger studies are needed to validate the safety of NIPPV in ARF of $\mathrm{dPH}$ and use with vasodilator and vasopressor therapies.

Hypoxemia and hypercapnia are causes of regional perfusion redistribution within the lung and can trigger local vasoconstriction of the lung. This leads to an increase in RV afterload, which increases RV oxygen demand and potentiates ischemia in patients with dPH. Prior to intubation, these patients are often trialed with high flow nasal cannula (HFNC) and/or NIPPV for optimization with variable success.

\section{Review of pharmacology and considerations}

RSI is a form of an advanced airway management commonly used in critically ill patients that uses a combination of medications to cause immediate unresponsiveness and muscular relaxation. Not every $\mathrm{dPH}$ requires RSI to perform ETI and some patients can undergo ETI with less sedation. A brief overview of commonly available induction agents is provided in Table 2. A critical challenge during RSI is avoiding exacerbation of hemodynamic instability

Table 2 Pharmacological options for rapid sequence intubation

\begin{tabular}{|c|c|c|c|c|c|}
\hline Drug & Mechanism & Advantages & Side effects & Dose & Duration of action \\
\hline \multicolumn{6}{|l|}{ Sedatives } \\
\hline Etomidate & $\begin{array}{l}\text { Ultra-short acting } \\
\text { nonbarbiturate general } \\
\text { anesthetic }\end{array}$ & $\begin{array}{l}\text { - Little effect on } \\
\text { hypotension }\end{array}$ & $\begin{array}{l}\text { - Suppresses adrenal } \\
\text { cortisol production }\end{array}$ & $0.2-0.6 \mathrm{mg} / \mathrm{kg}$ & $3-5 \min$ (dose-dependent) \\
\hline Ketamine & $\begin{array}{l}\text { NMDA and glutamate } \\
\text { receptor antagonist }\end{array}$ & $\begin{array}{l}\text { - Catecholamine } \\
\text { - Bronchodilation }\end{array}$ & $\begin{array}{l}\text { - May increase blood } \\
\text { pressure } \\
\text { - Raise ICP }\end{array}$ & $1-2 \mathrm{mg} / \mathrm{kg}$ & $15-30 \mathrm{~min}$ \\
\hline Midazolam & GABA receptor & - No reported advantage & $\begin{array}{l}\text { - Dose-dependent } \\
\text { reduction in myocardial } \\
\text { contractility } \\
\text { - Hypotension }\end{array}$ & $0.2-0.3 \mathrm{mg} / \mathrm{kg}$ & $1-6 \mathrm{~h}$ \\
\hline Propofol & $\begin{array}{l}\text { GABA receptor } \\
\text { modulator }\end{array}$ & - Bronchodilation & $\begin{array}{l}\text { - Suppress myocardial } \\
\text { contractility } \\
\text { - Hypotension } \\
\text { - Discolored urine (green } \\
\text { tint) } \\
\text { - Myoclonus }\end{array}$ & 1.5 to $3 \mathrm{mg} / \mathrm{kg}$ & $10 \mathrm{~min}$ \\
\hline \multicolumn{6}{|l|}{ NMBAs } \\
\hline Succinylcholine & $\begin{array}{l}\text { Depolarizing agent act- } \\
\text { ing on post-synaptic } \\
\text { cholinergic receptors of } \\
\text { the motor endplate }\end{array}$ & - Shortest acting & $\begin{array}{l}\text { - Many contraindications } \\
\text { - Malignant } \\
\text { hyperthermia } \\
\text { - Rhabdomyolysis } \\
\text { - Hyperkalemia } \\
\text { - Trismus/fasciculations } \\
\text { - Bradycardia } \\
\text { - Increased ICP }\end{array}$ & $1.5 \mathrm{mg} / \mathrm{kg}$ & $6-10 \mathrm{~min}$ \\
\hline Rocuronium & $\begin{array}{l}\text { Nondepolarizing agent } \\
\text { acting on synaptic } \\
\text { nicotinic receptors at the } \\
\text { neuromuscular junction }\end{array}$ & $\begin{array}{l}\text { - No effects on heart rate } \\
\text { or blood pressure }\end{array}$ & $\begin{array}{l}\text { - IgE-induced } \\
\text { anaphylaxis }\end{array}$ & $1-1.2 \mathrm{mg} / \mathrm{kg}$ & $45 \min$ \\
\hline Vecuronium & $\begin{array}{l}\text { Nondepolarizing agent } \\
\text { blocking the nicotinic } \\
\text { acetylcholine receptor } \\
\text { at the postjunctional } \\
\text { membrane of the } \\
\text { neuromuscular junction }\end{array}$ & - No reported advantage & $\begin{array}{l}\text { - Bronchospasm } \\
\text { - Hypotension } \\
\text { - Sinus tachycardia } \\
\text { - Erythema } \\
\text { - Urticaria } \\
\text { - Flushing } \\
\text { - Pruritus } \\
\text { - Hypersensitivity } \\
\text { - Anaphylaxis }\end{array}$ & $0.1-0.2 \mathrm{mg} / \mathrm{kg}$ & $45-60 \mathrm{~min}$ \\
\hline
\end{tabular}


in $\mathrm{dPH}$ patients. Expert opinion is founded on a few studies of induction of anesthesia in the critically ill, and on case reports/small studies on pre-operative $\mathrm{PH}$ patients undergoing obstetric or cardiac surgery. Etomidate and ketamine are commonly promoted as first line agents for ETI of dPH $[16,30]$. Induction with a two medication combination of propofol with high dose opioids or benzodiazepines should be avoided in this cohort due to their compounding negative effects on sympathetic tone and on cardiac contractility, preload, and afterload [30].

\section{Commonly debated themes surrounding rapid sequence intubation options}

While expert opinion and limited studies make suggestions for or against certain agents, mortality in $\mathrm{dPH}$ patients is more likely due to the proceduralist's misunderstanding of the following: (1) the pathophysiology in $\mathrm{dPH}$; (2) the anesthetic and hemodynamic goals of the intubation procedure; and (3) the pharmacology of the various drug options and how these medications relate to the hemodynamic goals.

\section{Propofol}

Propofol is associated with systemic hypotension by decreasing systemic vascular resistance, mean arterial pressure, and cardiac output. Additionally, it reduces the baroreceptor reflex, poses negative inotropic effects, and acts as a direct myocardial depressant $[31,32]$. Generally, it is recommended to avoid propofol in $\mathrm{dPH}$ patients due to its vasodilator and cardiac depressive properties which can trigger hemodynamic instability.

\section{Ketamine}

Ketamine is both a direct myocardial depressant as well as a sympathomimetic and as such may maintain or raise preinduction blood pressure. The contrasting properties may in part explain why ketamine has been shown to have more peri-intubation-related hypotensive events in comparison to etomidate in one observational study [33]. However, ketamine has also been shown to a reasonable alternative to maintain stable hemodynamics in one randomized controlled trial [34]. Ketamine is a reasonable option in dPH patients to minimize hypotension during RSI and improve coronary artery and end organ perfusion. Ketamine, in combination midazolam and rocuronium, have been utilized successfully with vasopressors for intubation in stable preoperative $\mathrm{PH}$ patients [35].

\section{Etomidate}

Etomidate has been demonstrated to have less hemodynamic effects compared to propofol in rodent models with PH [36]. Etomidate is associated with adrenal suppression which can result in delayed hypotension and hemodynamic collapse [34, 37]. Etomidate and ketamine have been shown to be comparable sedative options for endotracheal intubation in septic patients [34].

\section{Specific literature within pulmonary hypertension}

One small retrospective study has compared outcomes in 33 peri-operative patients with $\mathrm{PH}$ secondary to Eisenmenger syndrome or other similar cardiac defects [38]. While hypotension and hypoxia were common complications in stable perioperative $\mathrm{PH}$ patients, propofol was more commonly associated with hypotension than etomidate. However, this finding was not statistically significant and was limited by a small sample size, being conducted in a single center, and the nonrandomization of induction agent selection.

\section{Approach to intubation}

The decision to intubate a dPH patient should be tailored to the condition of the individual patient and the experience of the proceduralist. Common indications for intubation in $\mathrm{dPH}$ include progressive respiratory failure (hypoxic and/or hypercapnic), impaired consciousness with Glasgow Coma Scale less than or equal to 8 , worsening airway obstruction, and impending hemodynamic arrest. When preparing for ETI in a dPH patient, consideration of ECMO and lung transplantation or pulmonary endarterectomy candidacy is warranted. Cardiothoracic surgery should be engaged prior to intubation should the patient be considered as a candidate for any of these surgical interventions, and in case the patient decompensates despite maximum medical therapy post ETI. Figure 2 provides a checklist for the approach to intubation in dPH [39].

\section{Goals of care discussion}

When possible and prior to intubation, a discussion should be held which reviews the potential benefits and risks associated with this specific cohort. Due to its high risks, patients and their legal surrogate(s) should understand that periprocedural mortality is high. If the patient is not a candidate 


\section{Positioning and Plan}

11 Is it necessary to intubate? Can they tolerate SV, NIPPV, HFNC?

(1) Discuss code status with patient or legal surrogate

(1) Review prior airway data if available to have most likely successful plan in place

(1) Monitors in place? Pre-induction arterial line? Consider PAC?

(10) Optimize positioning. Head up during pre-oxygenation (maximize FRC). Supine for intubation after induction (sniffing, cricoid, tragus lined up with suprasternal notch) (10 Have functioning suction at bedside

\section{Pre-Oxygenation}

(1) Most experienced provider to place ETT (i.e Anesthesia, ICU attending)

(10Reassess volume status and cardiac function with bedside ultrasound

(1) Vasopressors in line. (consider Vasopressin-> least effect on PVR whilst maintaining SVR vs. Norepinephrine)

(1) Initiate Inotropic support for right heart as indicated (i.e Milrinone, Dobutamine, Epinephrine)

10Consider inhalant support during preoxygenation period (ie. HFNC) with plans to continue post-intubation. RT to have appropriate inhalant available (i.e Flolan vs. iNO)

(10) Prior to induction Optimize $\mathrm{O2}, \mathrm{CO}$, and Acid base status via arterial blood gas

10Optimize hemodyanmic status prior to induction

(10) Consider cricoid pressure, especially if NPO guidelines not met

\section{Modality Selection}

(1) Decision Point: maintain spontaneous ventilation vs. assisted

(1) Decision Point: If patient able to cooperate and follow commands $\rightarrow$ If an awake intubation a possibility

(1) If awake intubation not an option $\rightarrow$ Consider maintaining spontaneous respiration

(1) Similar to any intubation of a critically ill patient: Use best airway option first as determined by pre-induction assessment and prior airway notes if available

\section{Drug Selection}

10 Careful selection of induction agent dependent on goals (i.e Ketamine vs. Etomidate vs. Opioid)

(10) If spontaneous ventilation not an option $\rightarrow$ select appropriate paralytic to optimize intubating conditions

(1) Induce slowly with vasopressors in line

\section{Back-up Plan}

10Have multiple back-up intubation techniques available

(1) Know and be ready to apply the difficult airway algorithm

(1) Have plan for FONA available at bedside

(1) Consider VA-ECMO on stand-by

\section{Verification/Post-intubation}

\section{(10) Intubate}

10 Confirm successful intubation with usual techniques (auscultation, ETCO2, colormetric CO2 detector, CXR)

(10) Once endotracheal intubation confirmed, sit patient up, recruit lung segments slowly in order to optimize respiratory mechanics and avoid hemodynamic

decompensation from excessive positive pressure ventilation

(1) Initiate appropriate maintenance sedation

Fig. 2 Suggested algorithm on approach to intubation in dPH patients. Legend: CXR, chest X-ray; ETCO2, end tidal carbon dioxide; ETT, endotracheal tube; FONA, front of neck access; FRC, functional residual capacity; ICU, intensive care unit; PAC, pulmonary

for ECMO or lung transplantation, then clarifying realistic expectations is critical if the patient does not improve with optimized medical care. Anand et al. [40] found that palliative care services (PCS) were utilized in $2.2 \%$ of all $\mathrm{PH}$ patients and were significantly associated with longer arterial catheter; PVR, pulmonary vascular resistance; RT, respiratory therapist; SV, spontaneous ventilation; SVR, systemic vascular resistance; VA-ECMO, veno-arterial extracorporeal membrane oxygenation

hospital stays, higher hospitalization costs, and higher inhospital mortality. This likely reflects providers involving PCS in sicker patients and/or late in the hospital course, although the later was not well defined given that the study was performed using the National Inpatient Sample. 
Table 3 Risk factors for difficult intubation

\author{
Common risk factors \\ - Trauma \\ - Short neck \\ - Micrognathia \\ - Prior surgery \\ - Morbid obesity \\ 3-3-2 Evaluation \\ - 3: distance between incisor teeth with mouth fully open should be at least 3 finger breadths \\ - 3: distance between hyoid bone and anterior tip of mandible should be 3 finger breadths \\ - 2: distance between thyroid notch and mouth floor should be at least 2 finger breadths \\ Mallampati score \\ Higher score correlates with increased difficulty \\ Visible obstruction \\ i.e., Foreign body, abscess, tumor, hematoma \\ Neck mobility \\ Patient able to place their chin on their chest and fully extend their neck back
}

\section{Procedural preparation}

When preparing to institute respiratory support, the patient should have at the bedside a system for pre-oxygenation, a bag valve mask, a range of ET tubes, rescue devices, airway adjuncts (bougie, stylet), suction devices, laryngoscope, end tidal $\mathrm{CO} 2$ monitoring, ventilator, inhaled pulmonary vasodilators, vasopressors, inotropes, induction medications, and paralytics. Table 3 describes common assessment to predict difficulty with ET intubation. Table 4 provides an overview for the types of tracheal intubation.

Continuous telemetry, noninvasive blood pressure monitoring, and pulse oximetry are standard in critical care. An arterial line should be in place prior to the procedure for accurate blood pressure monitoring and for titration of vasoactive agents. If ECMO support is considered, a femoral arterial line is preferred. All dPH patients should have central access and at least two peripheral intravenous lines prior to intubation. If a pulmonary arterial (PA) catheter is unavailable, the central line should be used for central venous pressure monitoring and to measure mixed central venous saturation. PA catheterization should not delay emergent intubation. Intensivists may elect to use minimally invasive hemodynamic monitoring such as the FloTrac device, which uses arterial wave form analysis to provide hemodynamic information. In dPH patients, FloTrac device has been demonstrated in one small study and commentary to be inferior to the PA catheter in patients with a $\mathrm{CI}<2.2$ in determining accurate hemodynamic information using echocardiography in both groups $[41,42]$.

\section{Vasoactive agents}

The agent to use as first-line vasopressor in $\mathrm{dPH}$ is controversial and varies between institutions [43]. Expert opinion suggests that norepinephrine or vasopressin should be considered as first-line vasopressor in $\mathrm{dPH}$ patients [15]. Phenylephrine should not be used in this cohort as it may cause pulmonary arterial vasoconstriction and an increase in right ventricular afterload in an already failing and vulnerable RV [44]. Dobutamine and milrinone are inotropic agents that may be used to stabilize $\mathrm{dPH}$ patients and, if on, should be continued throughout the peri-intubation period.

Table 4 Overview of types of tracheal intubation commonly used in critical care setting

\begin{tabular}{|c|c|c|}
\hline Intubation type & Method options & Considerations \\
\hline Direct laryngoscopy & $\begin{array}{l}\text { - Via endotracheal or nasotracheal placement } \\
\text { - MacIntosh or Miller Blade }\end{array}$ & $\begin{array}{l}\text { Bougies may be used as adjuncts when laryngeal view is poor or } \\
\text { restricted }\end{array}$ \\
\hline Video laryngoscopy & - GlideScope, C-MAC, Olympus, McGrath Mac & $\begin{array}{l}\text { May provide improved glottis visualization } \\
\text { Allows visualization by other proceduralist in room }\end{array}$ \\
\hline Fiberoptic intubation & - With use of video-assisted fiberoptic bronchoscope & Strong recommendation for difficult to visualize glottis \\
\hline Cricothyrotomy & - Bedside surgical procedure & $\begin{array}{l}\text { Used when all other options have failed } \\
\text { May be used when above types have anatomical contraindications } \\
\text { such as tumors or fractures affecting the airway }\end{array}$ \\
\hline
\end{tabular}


Caution should be used with inotropic agents such as milrinone or dobutamine due to their systemic vasodilatory effects, as patients with systemic level pulmonary artery pressures may decompensate or cardiac arrest on initiation if systemic vascular resistance decreases without support [45-47]. Inhaled milrinone, by itself or in combination with inhaled prostacyclin, has been shown to be a promising as they improve mean pulmonary artery pressures and cardiac index, while having minimal to no effect on the systemic circulation [48-50].

\section{Pre-oxygenation and ventilation}

Patients should be pre-oxygenated judiciously to balance timing of the procedure and the levels of oxygen saturation. Preoxygenation increases patients' oxygen reserve to prevent or postpone arterial oxygen desaturation during apnea after RSI [51]. HFNC may be preferable to NIPPV to correct for hypoxia and avoid the negative effects of PEEP on the RV. The use of HFNC in combination with inhaled vasodilator may also improve hypercarbia. This occurs via (1) effects on reducing RV afterload through pulmonary vasodilation and (2) preferential vasodilation in better oxygenated areas of the lung which improves efficiency of gas exchange. Nasal cannula or HFNC may be continued during apnea and the peri-procedural process as a technique to minimize arterial oxygen desaturation [51].

\section{Pre-procedural PH therapy}

All chronic PAH-specific therapies should be continued throughout the intubation process to avoid rebound increases in PVR which can acutely worsen RV failure. Patients already on intravenous PH therapy medications (usually a prostacyclin) most often have an already preestablished central venous access catheter to receive therapy. This therapy should not be interrupted, nor should any other medications be mixed with this dedicated intravenous prostacyclin therapy access [52].

If continuous intravenous prostacyclin therapy has been initiated earlier in the ICU course, it should be maintained at the existing dose for hemodynamic stability. Likewise, if inhaled prostacyclin or nitric oxide is initiated prior to intubation, it would be recommended to continue this therapy during the peri-intubation process. Both these agents can be administered via HFNC or NIPPV, as well as via a mechanical ventilator.

\section{Immediate post-intubation complications and suggested prevention/management}

Impending circulatory failure in $\mathrm{PH}$ patients during intubation has been associated with decrease in MAP by $35 \%$ from baseline [20]. This acute decrease in MAP results in a reduction in RV perfusion potentially causing RV ischemia, depressed myocardial contractility, and impaired cardiac output. Vasopressors should be used post-intubation and through initiation of mechanical ventilation to maintain a MAP goal of $>65 \mathrm{mmHg}$.

Arrhythmias are common in patients with $\mathrm{PH}$ and restoration of sinus rhythm is desirable [53]. Antiarrhythmic agents such as amiodarone may be required and electrical cardioversion of unstable arrhythmias should be performed to rapidly restore sinus rhythm.

Positive pressure ventilation from mechanical ventilation causes increased intrathoracic pressure leading to increased RV afterload [54]. To reduce RV stress and myocardial oxygen demand, ventilator settings should adopt low PEEP and low tidal volume strategies in efforts to reduce plateau pressures. Permissive hypercarbia should be avoided as this can increase PVR and RV afterload [55].

Trending of central venous pressure, mixed venous saturations, arterial blood pressures, and oxygenation saturations are critical to monitor patients post-intubation to titrate vasopressors, vasodilators, inotropes, and mechanical ventilator settings.

\section{Emergence of awake intubation}

Awake flexible fiberoptic intubation (FOI) is considered the gold standard in the management of suspected difficult ETI. One multicenter randomized control trial compared 43 awake FOI patients and 41 awake VAL intubated patients using the McGrath Series 5 video laryngoscope. They found no difference in time to ETI between FOI and VAL [56]. Patients were intubated by a proceduralist trained in both techniques and most were successfully intubated on first attempt. This study is limited by the lack of blinding and the fact that the intubations were all performed during elective procedures. dPH patients are difficult airways in an emergent setting and would not be represented by this patient selection. One study showed that emergency department providers are less likely to rely on FOI during difficult intubations [57]. While this study did not include awake patients during difficult airway management, it is reasonable to infer that operators would still be uncomfortable using FOI in awake difficult airways. 
The modality selection in acute settings is likely dependent on proceduralist familiarity and device availability. Such that, an emergency department provider may feel natural with VAL or DL intubation [57] compared to a pulmonary trained intensivist who feels comfortable trialing FOI [58].

\section{Awake FOI in PH}

A case report described successful awake fiberoptic intubation of a critically ill patient with severe $\mathrm{PH}$ requiring emergent abdominal surgery [59]. Four percent lidocaine was used to anesthetize the posterior oropharynx, and $2 \%$ lidocaine was used to anesthetize the bilateral superior larynx and trachea. Multiple vasopressors, inotropes, and nitric oxide were started before intubation and were continued during the procedure. The patient was then sedated with midazolam and ketamine before diagnostic peritoneal lavage and ultimately died peri-procedurally from gross fecal peritonitis secondary to necrotic appendicitis and massive intraventricular thrombus.

A case series of nine patients demonstrated the feasibility of awake bronchoscopic intubation with NIPPV [7]. All patients had confirmed PAH and were experiencing acute hypoxic respiratory failure requiring emergent ETI. Patients were pre-oxygenated for a minimum of $15 \mathrm{~min}$ with either NIPPV or HFNC prior to ETI in the semi-recumbent position. Systemic hypotension with a new or increased vasopressor requirement was the most common complication post-intubation.

Awake FOI is a potential option in $\mathrm{dPH}$ patients and is limited by proceduralist familiarity and equipment availability. Awake FOI or VAL may be desirable in $\mathrm{dPH}$ due to the avoidance of RSI and its resulting hemodynamic risks. More studies are needed to clarify their safety and efficacy in $\mathrm{dPH}$ patients.

\section{Conclusion}

Intubation of $\mathrm{dPH}$ patients remains a clinical challenge for the intensivist. The approach to intubation of these patients is based on expert opinion and extrapolated from airway management of the general critically ill and left-sided heart failure populations. Any necessary procedure should be performed by an experienced proceduralist who understands the pathophysiology of $\mathrm{dPH}$, who is familiar with the various vasoactive and anesthetic agents, and who is comfortable with both DL or VAL and FOI. Ketamine and etomidate are the primary sedatives recommended during RSI within this cohort, despite limited evidence specifically within the $\mathrm{dPH}$ cohort. More studies are needed on the role of awake FOI in dPH patients.
Author contribution CV: conceptualization, investigation, writing - original draft, writing - review and editing, visualization; JR: conceptualization, writing - review and editing; JZ: conceptualization, writing - review and editing; SM: writing - original draft, visualization; HP: writing - review and editing; HA: writing - review and editing; AA: conceptualization, writing - review and editing, supervision. All authors read and approved the final manuscript.

\section{Declarations}

Ethics approval and consent to participate Not Applicable.

Consent for participants Not Applicable.

Consent for publication Not Applicable.

Conflict interests The authors declare no competing interests.

\section{References}

1. Simonneau G, Montani D, Celermajer DS et al (2019) Haemodynamic definitions and updated clinical classification of pulmonary hypertension. Eur Respir J 53. https://doi.org/10.1183/13993003. 01913-2018

2. Olsson KM, Halank M, Egenlauf B et al (2018) Decompensated right heart failure, intensive care and perioperative management in patients with pulmonary hypertension: updated recommendations from the Cologne Consensus Conference 2018. Int J Cardiol 272:46-52. https://doi.org/10.1016/j.ijcard.2018.08.081

3. Savale L, Weatherald J, Jaïs X et al (2017) Acute decompensated pulmonary hypertension. Eur Respir Rev 26:170092. https://doi. org/10.1183/16000617.0092-2017

4. Vahdatpour C, Collins D, Goldberg S (2019) Cardiogenic Shock JAHA 8. https://doi.org/10.1161/JAHA.119.011991

5. Konstam MA, Kiernan MS, Bernstein D et al (2018) Evaluation and management of right-sided heart failure: a scientific statement from the American Heart Association Circulation 137. https://doi. org/10.1161/CIR.0000000000000560

6. Myles PS, Hall JL, Berry CB, Esmore DS (1994) Primary pulmonary hypertension: prolonged cardiac arrest and successful resuscitation following induction of anesthesia for heart-lung transplantation. J Cardiothorac Vasc Anesth 8:678-681. https:// doi.org/10.1016/1053-0770(94)90203-8

7. Johannes J, Berlin DA, Patel P et al (2017) A technique of awake bronchoscopic endotracheal intubation for respiratory failure in patients with right heart failure and pulmonary hypertension: Crit Care Med. 45:e980-e984. https://doi.org/10.1097/ CCM.0000000000002586

8. Perbet S, De Jong A, Delmas J et al (2015) Incidence of and risk factors for severe cardiovascular collapse after endotracheal intubation in the ICU: a multicenter observational study. Crit Care 19:257. https://doi.org/10.1186/s13054-015-0975-9

9. Schwartz DE, Matthay MA, Cohen NH (1995) Death and other complications of emergency airway management in critically ill adults: a prospective investigation of 297 tracheal intubations. Anesthesiology 82:367-376. https://doi.org/10.1097/00000542199502000-00007

10. Schwab TM, Greaves TH (1998) Cardiac arrest as a possible sequela of critical airway management and intubation. Am J Emerg Med 16:609-612. https://doi.org/10.1016/S0735-6757(98) 90229-7 
11. Mort TC (2004) The incidence and risk factors for cardiac arrest during emergency tracheal intubation: a justification for incorporating the ASA Guidelines in the remote location. J Clin Anesth 16:508-516. https://doi.org/10.1016/j.jclinane.2004.01.007

12. Lascarrou JB, Boisrame-Helms J, Bailly A et al (2017) Video laryngoscopy vs direct laryngoscopy on successful first-pass orotracheal intubation among ICU patients: a randomized clinical trial. JAMA 317:483. https://doi.org/10.1001/jama.2016.20603

13. Schettino G, Altobelli N, Kacmarek RM (2008) Noninvasive positive-pressure ventilation in acute respiratory failure outside clinical trials: experience at the Massachusetts General Hospital. Crit Care Med 36:441-447. https://doi.org/10.1097/01.CCM. 0000300084.67277 .90

14. Delclaux C, L'Her E, Alberti C et al (2000) Treatment of acute hypoxemic nonhypercapnic respiratory insufficiency with continuous positive airway pressure delivered by a face mask: a randomized controlled trial. JAMA 284:2352-2360. https://doi.org/ 10.1001/jama.284.18.2352

15. Hoeper MM, Benza RL, Corris $P$ et al (2018) Intensive care, right ventricular support and lung transplantation in patients with pulmonary hypertension. Eur Respir J 1801906. https://doi.org/10. 1183/13993003.01906-2018

16. Hoeper MM, Granton J (2011) Intensive care unit management of patients with severe pulmonary hypertension and right heart failure. Am J Respir Crit Care Med 184:1114-1124. https://doi. org/10.1164/rccm.201104-0662CI

17. Sanz J, García-Alvarez A, Fernández-Friera L et al (2012) Right ventriculo-arterial coupling in pulmonary hypertension: a magnetic resonance study. Heart 98:238-243. https://doi.org/10.1136/ heartjnl-2011-300462

18. Tello K, Dalmer A, Axmann J et al (2019) Reserve of right ventricular-arterial coupling in the setting of chronic overload. Circ Heart Fail 12. https://doi.org/10.1161/CIRCHEARTFAILURE. 118.005512

19. Vonk Noordegraaf A, Chin KM, Haddad F et al (2018) Pathophysiology of the right ventricle and of the pulmonary circulation in pulmonary hypertension: an update. Eur Respir J 1801900. https:// doi.org/10.1183/13993003.01900-2018

20. Höhn L, Schweizer A, Morel DR et al (1999) Circulatory failure after anesthesia induction in a patient with severe primary pulmonary hypertension: anesthesiology 91:1943. https://doi.org/10. 1097/00000542-199912000-00048

21. Dalabih M, Rischard F, Mosier JM (2014) What's new: the management of acute right ventricular decompensation of chronic pulmonary hypertension. Intensive Care Med 40:1930-1933. https:// doi.org/10.1007/s00134-014-3459-5

22. Rush B, Biagioni BJ, Berger L, McDermid R (2017) Mechanical ventilation outcomes in patients with pulmonary hypertension in the United States: a national retrospective cohort analysis. J Intensive Care Med 32:588-592. https://doi.org/10. 1177/0885066616653926

23. Campo A, Mathai SC, Le Pavec J et al (2011) Outcomes of hospitalisation for right heart failure in pulmonary arterial hypertension. Eur Respir J 38:359-367. https://doi.org/10.1183/09031936. 00148310

24. Höhn L, Licker M (2000) Extreme pulmonary hypertension and anesthesia induction. Anesthesiology 93:903-904. https://doi.org/ 10.1097/00000542-200009000-00051

25. Sandoval J, Alvarado P, Martínez-Guerra ML et al (1999) Effect of body position changes on pulmonary gas exchange in Eisenmenger's syndrome. Am J Respir Crit Care Med 159:1070-1073. https://doi.org/10.1164/ajrccm.159.4.9612071

26. Zeuzem-Lampert C, Groene P, Brummer V, Hofmann-Kiefer K (2019) Kardiorespiratorische Effekte perioperativer Positionierungsmaßnahmen. Anaesthesist 68:805-813. https://doi.org/ 10.1007/s00101-019-00674-9
27. Hirvonen EA, Nuutinen LS, Kauko M (1995) Hemodynamic changes due to Trendelenburg positioning and pneumoperitoneum during laparoscopic hysterectomy. Acta Anaesthesiol Scand 39:949-955. https://doi.org/10.1111/j.1399-6576.1995.tb04203.x

28. Duggan M, Kavanagh BP (2005) Pulmonary atelectasis: a pathogenic perioperative entity. Anesthesiology 102:838-854. https:// doi.org/10.1097/00000542-200504000-00021

29. Olsson KM, Frank A, Fuge J et al (2015) Acute hemodynamic effects of adaptive servoventilation in patients with pre-capillary and post-capillary pulmonary hypertension. Respir Res 16 . https:// doi.org/10.1186/s12931-015-0298-z

30. Schisler T, Marquez JM, Hilmi I, Subramaniam K (2017) Pulmonary hypertensive crisis on induction of anesthesia. Semin Cardiothorac Vasc Anesth 21:105-113. https://doi.org/10.1177/ 1089253216652222

31. Shafer SL, Rathmell JP, Stoelting RK (2015) Stoelting's pharmacology and physiology in anesthetic practice

32. Manchec B, Liu B, Tran T et al (2019) Sedation with propofol during catheter-directed thrombolysis for acute submassive pulmonary embolism is associated with increased mortality. J Vasc Interv Radiol 30:1719-1724. https://doi.org/10.1016/j.jvir.2019.08.009

33. April MD, Arana A, Schauer SG et al (2020) Ketamine versus etomidate and peri-intubation hypotension: a national emergency airway registry study. Acad Emerg Med 27:1106-1115. https:// doi.org/10.1111/acem.14063

34. Jabre P, Combes X, Lapostolle F et al (2009) Etomidate versus ketamine for rapid sequence intubation in acutely ill patients: a multicentre randomised controlled trial. The Lancet 374:293-300. https://doi.org/10.1016/S0140-6736(09)60949-1

35. Yim CF, Lim KS, Low TC (2002) Severe pulmonary hypertension in a patient with bronchiectasis complicated by cor pulmonale and a right-to-left shunt presenting for surgery. Anaesth Intensive Care 30:467-471. https://doi.org/10.1177/0310057X0203000412

36. Ouédraogo N, Mounkaïla B, Crevel H et al (2006) Effect of propofol and etomidate on normoxic and chronically hypoxic pulmonary artery. BMC Anesthesiol 6:2. https://doi.org/10.1186/ 1471-2253-6-2

37. Smischney NJ, Nicholson WT, Brown DR et al (2019) Ketamine/ propofol admixture vs etomidate for intubation in the critically ill: KEEP PACE Randomized clinical trial. J Trauma Acute Care Surg 87:883-891. https://doi.org/10.1097/TA.0000000000002448

38. Bennett JM, Ehrenfeld JM, Markham L, Eagle SS (2014) Anesthetic management and outcomes for patients with pulmonary hypertension and intracardiac shunts and Eisenmenger syndrome: a review of institutional experience. J Clin Anesth 26:286-293. https://doi.org/10.1016/j.jclinane.2013.11.022

39. De Backer D, Biston P, Devriendt J et al (2010) Comparison of dopamine and norepinephrine in the treatment of shock. N Engl J Med 362:779-789. https://doi.org/10.1056/NEJMoa0907118

40. Anand V, Vallabhajosyula S, Cheungpasitporn W et al (2020) Inpatient palliative care use in patients with pulmonary arterial hypertension: temporal trends, predictors, and outcomes. Chest 158:2568-2578. https://doi.org/10.1016/j.chest.2020.07.079

41. Power P, Bone A, Simpson N et al (2017) Comparison of pulmonary artery catheter, echocardiography, and arterial waveform analysis monitoring in predicting the hemodynamic state during and after cardiac surgery. Int J Crit Illn Inj Sci 7:156. https://doi. org/10.4103/2229-5151.214411

42. Botsch A, Firstenberg MS (2017) Comment on the Edwards FloTrac $^{\mathrm{TM}} /$ Vigileo versus pulmonary artery catheter study: what is really going on with this patient? Int J Crit Illn Inj Sci 7:183-184. https://doi.org/10.4103/IJCIIS.IJCIIS_44_17

43. Ryan JJ, Butrous G, Maron BA (2014) The heterogeneity of clinical practice patterns among an international cohort of pulmonary arterial hypertension experts. Pulm Circ 4:441-451. https://doi. org/10.1086/677357 
44. Kwak YL, Lee CS, Park YH, Hong YW (2002) The effect of phenylephrine and norepinephrine in patients with chronic pulmonary hypertension*: phenylephrine and norepinephrine in pulmonary hypertension. Anaesthesia 57:9-14. https://doi.org/10.1046/j. 1365-2044.2002.02324.x

45. Price LC, Wort SJ, Finney SJ et al (2010) Pulmonary vascular and right ventricular dysfunction in adult critical care: current and emerging options for management: a systematic literature review. Crit Care 14:R169. https://doi.org/10.1186/cc9264

46. Harjola V-P, Mebazaa A, Čelutkienè J et al (2016) Contemporary management of acute right ventricular failure: a statement from the Heart Failure Association and the Working Group on Pulmonary Circulation and Right Ventricular Function of the European Society of Cardiology: Contemporary management of acute RV failure. Eur J Heart Fail 18:226-241. https://doi.org/10.1002/ejhf.478

47. Tsapenko MV, Tsapenko AV, Comfere TB et al (2008) Arterial pulmonary hypertension in noncardiac intensive care unit. Vasc Health Risk Manag 4:1043-1060. https://doi.org/10.2147/vhrm.s3998

48. Theodoraki K, Thanopoulos A, Rellia P et al (2017) A retrospective comparison of inhaled milrinone and iloprost in post-bypass pulmonary hypertension. Heart Vessels 32:1488-1497. https:// doi.org/10.1007/s00380-017-1023-2

49. Laflamme M, Perrault LP, Carrier M et al (2015) Preliminary experience with combined inhaled milrinone and prostacyclin in cardiac surgical patients with pulmonary hypertension. J Cardiothorac Vasc Anesth 29:38-45. https://doi.org/10.1053/j.jvca.2014.06.012

50. Couture EJ, Tremblay J-A, Elmi-Sarabi M et al (2019) Noninvasive administration of inhaled epoprostenol and inhaled milrinone in extubated, spontaneously breathing patients with right ventricular failure and portal hypertension: a report of 2 cases. A \& A Practice 12:208-211. https://doi.org/10.1213/XAA.0000000000000886

51. Langeron O, Bourgain J-L, Francon D et al (2018) Difficult intubation and extubation in adult anaesthesia. Anaesth Crit Care Pain Med 37:639-651. https://doi.org/10.1016/j.accpm.2018.03.013
52. Coons JC, Clarke M, Wanek MR et al (2013) Safe and effective use of prostacyclins to treat pulmonary arterial hypertension. Am J Health Syst Pharm 70:1716-1723. https://doi.org/10.2146/ajhp130005

53. Cirulis MM, Ryan JJ, Archer SL (2019) Pathophysiology, incidence, management, and consequences of cardiac arrhythmia in pulmonary arterial hypertension and chronic thromboembolic pulmonary hypertension. Pulmonary Circulation 9:204589401983489. https://doi.org/10.1177/2045894019834890

54. Mahmood SS, Pinsky MR (2018) Heart-lung interactions during mechanical ventilation: the basics. Ann Transl Med 6:349-349. https://doi.org/10.21037/atm.2018.04.29

55. Wilcox SR, Kabrhel C, Channick RN (2015) Pulmonary hypertension and right ventricular failure in emergency medicine. Ann Emerg Med 66:619-628. https://doi.org/10.1016/j.annemergmed. 2015.07.525

56. Rosenstock CV, Thøgersen B, Afshari A et al (2012) Awake fiberoptic or awake video laryngoscopic tracheal intubation in patients with anticipated difficult airway management. Anesthesiology 116:1210-1216. https://doi.org/10.1097/ALN.0b013e318254d085

57. Sakles JC, Douglas MJK, Hypes CD et al (2017) Management of patients with predicted difficult airways in an academic emergency department. J Emerg Med 53:163-171. https://doi.org/10.1016/j. jemermed.2017.04.003

58. Vianello AMA, Arcaro GME, Braccioni FS et al (2007) Management of tracheal intubation in the respiratory intensive care unit by pulmonary physicians. Respir Care 52:26-30

59. Maxwell BG, Pearl RG, Kudelko KT et al (2012) CASE 7-2012 Airway management and perioperative decision making in the patient with severe pulmonary hypertension who requires emergency noncardiac surgery. J Cardiothorac Vasc Anesth 26:940944. https://doi.org/10.1053/j.jvca.2012.06.018

Publisher's Note Springer Nature remains neutral with regard to jurisdictional claims in published maps and institutional affiliations. 